\title{
Emotional Intelligence And Cross-Cultural Communication Competence: An Analysis Of Group Dynamics And Interpersonal Relationships In A Diverse Classroom
}

Melvin C. Washington, Howard University, USA

Ephraim A. Okoro, Howard University, USA

Sussie U. Okoro, Howard University, USA

\begin{abstract}
This study discusses the significance of emotional intelligence and intercultural communication competence in globally diverse classroom settings. Specifically, the research shows a correlation between degrees of emotional intelligence and human communication competence (age, gender, and culture). The dataset consists of 364 participants. Nearly six tenths $(n=215 ; 59.1 \%)$ were women. About two-thirds of participants were undergraduate students $(n=243 ; 66.8 \%)$, and onethird were graduate students $(n=121 ; 33.2 \%)$. Further, most respondents were African American $(n=303 ; 83.2 \%)$. The remaining students were of African and Caribbean origin $(n=$ 61; 61.8\%). Among the African/Caribbean students, they had the following national origins: Nigerian, 45 students; Jamaican, 5, Ghanaian, 4; Ugandan, 3; Trinidadian, 2; and Liberian, 2.
\end{abstract}

Keywords: Emotional Intelligence; Intercultural Communication; Communication Competence; Multicultural Classroom

\section{INTRODUCTION}

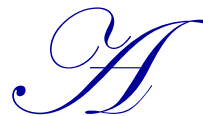

s today's academic environments and classrooms are becoming increasingly multicultural, diversified, and global, it becomes exceedingly significant to periodically assess the interaction among people who have different cultural backgrounds and orientations. Several scholars have noted the critical need of evaluating and understanding emotional intelligence in analyzing human communication and group interactions, especially in higher education contexts (Low et al., 2004; Vandervoort, 2006). A number of authors suggest that focusing on emotional intelligence could lead to a variety of positive personal, social, and societal outcomes, thus creating a more holistic approach to learning. Additionally, with higher degrees of emotional intelligence, students are more apt to make wise career choices (Gelso \& Fretz, 2001), reduce behavioral problems that may interfere with academic achievement (Cohen, 1999), score higher on standardized achievement tests (Hawkins, Von Cleave \& Catalano, 1991), and have an increased ability to solve problems (Goleman, 1995). Analogous to the importance of emotional intelligence in analyzing the interactions of students in higher education is the students' level of communication competence (Imahori \& Cupach, 2005).

This study, therefore, attempts to explicate the relationship between intercultural communication competence and emotional intelligence in an increasingly globally diverse university classroom. It examines current literature on both emotional intelligence and communication competence and their interplay in a learning community. The following research questions guided the study: (a) how do gender and culture affect the degree of emotional intelligence in globally diverse classroom settings; (b) how do gender and culture affect the degree of communicative competence in globally diverse classroom settings; and (c) how is emotional intelligence a predictor of communicative competence? 


\section{LITERATURE REVIEW}

Scholars and practitioners have defined Emotional Intelligence (EI) from a range of differing perspectives, and the concept has received a widespread attention over the past two decades as a critical factor in predicting, understanding, and analyzing human behavior both at work and in classrooms. A seminal work by Goleman (1998) described emotional intelligence based on five specific dimensions and twenty-five competencies. In another study, Goleman (2001) summarized emotional intelligence in four categorical dimensions comprised of twenty practical competencies. Furthermore, Wong \& Law (2002) analyzed and expanded the scope of Mayer \& Salovey's (1997) research and condensed emotional intelligence elements to four functional variables: appraisal and expression of emotion in the self (self emotional appraisal or SEA, appraisal and recognition of emotion in others (other's emotional appraisal, regulation of emotion in the self (regulation of emotion or ROE),, and use of emotion to facilitate performance (use of emotion or UOE).

Wong \& Law (2002) analysis of emotional intelligence was considered applicable in many human situations. Appraisal and expression of emotion in the self is associated with individuals' ability to comprehend deep-seated emotions and the capacity to adequately express themselves in natural settings. In other words, human beings who have high ability in this area are able to sense their emotions well before other people in the same environment. The authors explained that appraisal and recognition of emotion in others can be associated with individuals' ability to assess and understand human emotions in their immediate surroundings. It is then stated that individuals who are high in this category are more sensitive to the emotions of other people and can make effective determination of their thinking. Additionally regulation of emotion in the self is clearly associated with the ability of an individual to control his or her emotions, which allows for quick response to unfavorable situations, such as stress or distressful events. Finally, Wong and Law see the use of emotion to facilitate performance as the capacity to utilize emotions toward constructive and effective human activities. People in this category are often able to use their emotions to facilitate positive performance both in the workplace and in the learning environments, such as the classroom.

\section{METHODOLOGY: SURVEY INSTRUMENTS}

Essentially, the survey instrument for this study was developed to assess the degree of emotional intelligence and communication competency in each of the respondents. The first portion of the survey focused on the assessment of the respondent's degree of emotional intelligence was originally generated in Wong, Law, and Song (2002) in a study to determine a psychometrically sound and practically short emotional intelligence measure that could be used in leadership and management studies. The instrument was later modified by Yarrish and Law (2009) according to the four-dimensional definition of emotional intelligence in Davies, Stankov, and Roberts (1998) that investigated the relationship among measures of emotional intelligence, traditional human cognitive abilities, and personality. The four dimensions are self-emotions appraisal, others-emotions appraisal, use of emotion, and regulation of emotion. After the elimination of items because of inappropriateness or factor loading, four items for each dimension were selected resulting in a sixteen item survey.

The second portion of the survey utilized the Communicative Competence Scale (CCS) to assess the respondent's degree of communicative competence. It was generated by Wiemann (1977) to measure the ability "to choose among available communicative behaviors" to accomplish one's own "interpersonal goals during an encounter while maintaining the face and line" of "fellow interactants within the constraints of the situation" (p. 198). During that original study, the CCS reported a .96 coefficient alpha for 57 Likert-type items and a (.74 magnitude of experimental effect) for the 36-item revised instrument. The CCS is used to assess another person's communicative competence by responding to 36 items using Likert scales a range from strongly agree (5) to strongly disagree (1). The scale takes less than 5 minutes to complete and was created to assess five dimensions of interpersonal competence; general competence, empathy, affiliation/support, behavioral flexibility, and social relaxation (Rubin, Palmgreen \&Sypher,1994). 


\section{PROCEDURES}

This study was conducted at two Historical Black College and Universities (HBCU), in the eastern part of the United States. The researchers were interested in conducting intercultural communication study of students' emotional intelligence as a predictor of their communication competence in globally diverse classroom settings. In order to determine whether the instrument was understandable within the context that it was given, a pre-test survey was conducted in the Fall 2011 semester. The questionnaires were administered by graduate assistants during the normal class hours of the represented population. Each participant was informed that the survey was a practice run and that the assignment was to determine the strengths and weaknesses of the survey. Fifteen (15) participants were asked to explain their reactions to the question form, wording, and order. Each questionnaire was completed by hand and turned in to the graduate assistant. The final research tool was administered during the Spring 2012 semester.

\section{DEMOGRAPHICS}

There were a total of 364 participants, and approximately six-tenths $(n=215 ; 59.1 \%)$ were women. About two thirds of the participants were undergraduate $(\mathrm{n}=243 ; 66.8 \%)$ and one third were graduate students $(\mathrm{n}=121$; $33.2 \%)$. Most respondents were African American $(n=303 ; 83.2 \%)$. The remaining students were of African and Caribbean origin $(\mathrm{n}=61 ; 61.8 \%)$. Among the African/Caribbean students, they had the following national origins: Nigerian, 45 students; Jamaican, 5, Ghanaian, 4; Ugandan, 3; Trinidadian, 2; and Liberian, 2.

\section{RESULTS}

Based on Tukey post-hoc test, a superscript of 1 indicates significant difference with African American men; a superscript of 2 indicates a significant difference with African/Caribbean men; a superscript of 3 indicates a significant difference with African American women; and a superscript of 4 indicates a significant difference with African/Caribbean women.

As shown in Table 1, the results indicated that (1) women from African and the Caribbean report higher self-emotions appraisal, (2) African American women report higher other-emotions appraisal than African men, and (3) African/Caribbean men report higher regulation of emotion than African/Caribbean women and African American men and women.

Table $1 *$. ANOVA Test of Differences by Culture and Gender

\begin{tabular}{|c|c|c|c|c|c|}
\hline & $\underline{n}$ & $\underline{M}$ & $\underline{S D}$ & $\underline{F}$ & $\underline{P}$ \\
\hline Self-emotions appraisal & & & & 2.63 & $.05 *$ \\
\hline African American Men & 121 & 16.65 & 2.80 & & \\
\hline African/Caribbean Men & 26 & 16.85 & 2.01 & & \\
\hline African American Women ${ }^{4}$ & 180 & 16.21 & 2.29 & & \\
\hline African/Caribbean Women ${ }^{3}$ & 35 & 17.34 & 1.71 & & \\
\hline Total & 362 & 16.51 & 2.42 & & \\
\hline Other-emotions appraisal & & & & 2.58 & $.05^{*}$ \\
\hline African American Men & 121 & 11.34 & 2.12 & & \\
\hline African/Caribbean $\mathrm{Men}^{3}$ & 26 & 10.46 & 1.45 & & \\
\hline African American Women ${ }^{2}$ & 180 & 11.51 & 1.71 & & \\
\hline African/Caribbean Women & 35 & 11.31 & 1.08 & & \\
\hline Total & 362 & 11.36 & 1.81 & & \\
\hline Use of emotion & & & & .90 & .44 \\
\hline African American Men & 121 & 16.64 & 2.61 & & \\
\hline African/Caribbean Men & 26 & 17.35 & 1.50 & & \\
\hline African American Women & 180 & 16.91 & 2.75 & & \\
\hline African/Caribbean Women & 35 & 17.26 & 2.13 & & \\
\hline Total & 362 & 16.88 & 2.58 & & \\
\hline Regulation of emotion & & & & 6.93 & $.00 * *$ \\
\hline African American $\mathrm{Men}^{2}$ & 121 & 15.52 & 2.96 & & \\
\hline African/Caribbean Men ${ }^{1,3,4}$ & 26 & 17.69 & 5.53 & & \\
\hline African American Women ${ }^{2}$ & 180 & 14.96 & 2.66 & & \\
\hline
\end{tabular}




\begin{tabular}{|c|c|c|c|c|c|}
\hline $\begin{array}{l}\text { African/Caribbean Women }{ }^{2} \\
\text { Total }\end{array}$ & $\begin{array}{c}35 \\
362\end{array}$ & $\begin{array}{l}14.54 \\
15.30\end{array}$ & $\begin{array}{l}2.86 \\
3.14\end{array}$ & & \\
\hline Communication Competence Level & & & & .53 & .66 \\
\hline African American Men & 117 & 133.86 & 16.31 & & \\
\hline African/Caribbean Men & 25 & 133.92 & 12.99 & & \\
\hline African American Women & 167 & 134.80 & 10.70 & & \\
\hline African/Caribbean Women & 28 & 131.57 & 9.01 & & \\
\hline Total & 337 & 134.14 & 12.95 & & \\
\hline
\end{tabular}

Note. ${ }^{*} \mathrm{p}<.05 ; * * \mathrm{p}<.01$.

As shown in Table 2, regressions of communication competency based on the dimensions of emotional intelligence found that all emotional intelligence (EI) dimensions predict communication competency. In addition, other-emotions appraisal and use of emotion appraisal have the most impact.

Table 2*. Regressions of Communication Competency Level based On Emotional Intelligence Dimensions

\begin{tabular}{rlcccc}
\hline \multicolumn{2}{c}{} & $\underline{B}$ & $\underline{S E}$ & $\underline{\underline{t}}$ \\
\hline (Constant) & 58.11 & 5.271 & 11.02 & $.00^{* *}$ \\
1. & Other-emotions appraisal & 2.95 & 0.316 & 9.31 & $.00^{* *}$ \\
2. $\quad$ Use of emotion & 1.48 & 0.23 & 6.41 & $.00^{* *}$ \\
3. & Regulation of emotion & 0.61 & 0.182 & 3.36 & $.00^{* *}$ \\
$4 . \quad$ Self-emotions appraisal & 0.50 & 0.257 & 1.96 & $.05^{*}$ \\
\hline
\end{tabular}

\section{OBJECTIVE AND DISCUSSION}

The purpose of this study was two-fold. First, to investigate if student's' degree of emotional intelligence and communication competence were influenced by gender and culture in a globally diverse classroom settings. This purpose was discussed based on the research questions listed below: (1) how do gender and culture affect the degree of emotional intelligence in globally diverse classroom settings?

Results of an ANOVA test of differences by age and culture revealed three significant findings, all of which dealt with emotional intelligence. The first significant finding was that students from Africa and the Caribbean reported higher self-emotions appraisal than African-American students. That is, students from Africa and the Caribbean reported having a higher degree of understanding and recognizing of their own feelings and emotions than African-American students. This finding reinforces the literature on the emotional intelligence of foreign students. Furthermore, Fatt and Howe (2003) found that foreign undergraduate students have a higher emotional intelligence (EI) score for self-emotion than those with a local educational background. In another study, Carr (2009) discovered that Asian students, studying in the USA achieved higher scores in all branches of emotional intelligence. The results of these studies as well as the present one could be attributed to a need to assimilate into the dominate culture by the students from Africa and the Caribbean. When individuals assimilate, they do not want to maintain an isolated cultural identity, but rather want to maintain relationships with new cultures (Martin \& Nakayama (2007). Therefore, it is no surprise that students who want to fit in would make a conscious effort to be fully aware of their own feelings in order to communicate more effectively interpersonally and in group contexts.

The second significant finding was that African- American women reported higher other-emotions appraisal than African men. That is, African-American women reported a higher degree of understanding and recognizing of other peoples' feelings and emotions than African men. Again, this notion is congruent with much of the literature on emotional intelligence and gender. Interestingly, majority of studies have discovered that females have higher degrees of emotional intelligence than males. For instance, females exhibit higher levels of interpersonal emotional intelligence and coping styles than males (Alumran \& Punamaki, 2008), and were therefore more capable to handle the stress of demands and challenges. Similarly, Lyusin (2006) found that females are better at sensing the emotions of other people and have a greater tendency toward psychological analysis of other people's behavior. This phenomenon can be found in university classrooms where females are found to be more emotionally attached to the faculty. Conversely, there is a growing body of research that suggests that males have a higher degree of emotional intelligence. Fatt and Howe (2003) explained that men are more self-confident and can handle stress better than their female counterparts. Similarly, in another study, Carr (2009) discovered that although both male 
and female students attained emotional intelligence (EI) scores, in the competent level male medical students had higher scores. These results may then be attributed to African-American women being more comfortable in their local setting than the African men.

The third finding was that African/Caribbean men reported a higher regulation of emotion than African/Caribbean women and African American men and women. That is, African/ Caribbean men reported being able to control their emotions more than African/Caribbean women and African American men and women. The result of an ANOVA test indicates that research question (2), how do gender and culture affect the degree of communicative competence in globally diverse classroom settings had no significant findings in the degree to which gender or culture affects the level of communicative competence. Finally, results of regression analysis of communication competency levels based on emotional intelligence dimensions indicated that emotional intelligence (EI) predicted communication competency, with other-emotions appraisal and use of emotion having the most impact.

\section{CONCLUSION}

Over the past decades, emotional intelligence has been a major topic of scholarly investigation and analysis, and human differences indicate the need to acquire emotional intelligence skills in order to cultivate and sustain a lasting relationship in a multicultural learning environment. This study clearly demonstrates that in our contemporary higher education classrooms and workplaces intercultural sensitivity, interpersonal communication competence, and knowledge of human diversity are fundamental keys to successful endeavors. Essentially, many business organizations, colleges, and universities are establishing training programs as strategic ways to enhance students' knowledge and abilities for increased intercultural communication competence and respectful relationships in diverse settings. Indeed, managing diversity has been a primary challenge for many organizations and academic institutions; therefore, emotional intelligence is significant for understanding intercultural awareness and for an appreciation of diversity. The result of this study shows that emotional intelligence is closely associated with or related to higher levels of intercultural growth and sensitivity and should be required of people in leadership and teaching positions. Effective instructions in globally diverse classrooms place strong emphasis on the development and application of emotional intelligence skills.

\section{AUTHORS INFORMATION}

Melvin C. Washington, $\mathrm{PhD}$ is an assistant professor of business and management communication at Howard University. He is the core course coordinator for the business communication program in the School of Business, Department of Marketing. His research focuses on intercultural communication, organizational communication, and critical pedagogy. Address correspondence to Melvin C. Washington, Howard University School of Business, 2600 $6^{\text {th }}$ Street N.W., Washington, D.C. 20059. E-mail: $\underline{\text { m_c_washington@ @ howard.edu }}$

Ephraim A. Okoro, $\mathrm{PhD}$, is an assistant professor of business communication and marketing at Howard University. His research interests probe the interface between intercultural communication and workforce diversity in the context of globalization. Address correspondence to Dr. Ephraim Okoro, Department of Marketing, School of Business, Howard University, 2600 - Sixth Street, NW, Washington, D.C. 20059. E-mail: eaokoro@ howard.edu (Corresponding author)

Sussie U. Okoro is a PhD candidate in the Department of African Studies at Howard University. She is a teaching associate in the department and her research focus is on gender, culture, and development. Address correspondence to Ms. Sussie Okoro, Howard University, African Studies and Research Department. E-mail: suokoro92@gmail.com

\section{REFERENCES}

1. Cohen, J. (ed.) (1999). Educating minds and hearts: Social emotional learning and the passage into adolescence. New York: Teachers College Press. 
2. Davies, Michaela, Stankov, Lazar, \& Roberts, Richard D. (1998). Emotional intelligence: In search of an elusive construct. Journal of Personality and Social Psychology, 75(4), 989-1015.

3. Gelso, C. \& Fretz, B. (2001). Counseling Psychology, $2^{\text {nd }}$ Ed. Belmont, CA: Wadsworth.

4. Goleman, D. (1998 Nov-Dec). What Makes a Leader? Harvard Business Review.

5. Goleman, D., Boyatzis, R., \& McKee, A. (2001). Primal Leadership: The Hidden Driver of Great Performance. Harvard Business Review, 79(11), 42-51

6. $\quad$ Goleman, D. (1995). Emotional intelligence. New York: Bantam Books.

7. Hawkins, J.D., Von Cleave, E. \& Catalano, R.F. (1991). Reducing early childhood aggression: Results of a primary prevention program, Journal of the American Academy of Child and Adolescent Psychiatry, 30, 208-217.

8. Imahori, T.T. \& Cupach, W.R. (2005). Identity Management Theory: Facework in intercultural relationships. In W.B. Gudykunst. Theorizing About Intercultural Communication (pp. 195-210. Thousand Oaks: Sage.

9. Leathwood, C., \& Hey, V. (2009). Gender/ed discourses and emotional sub-texts: theorising emotion in UK higher education. Teaching in Higher Education, 14(4), 429-440. doi:10.1080/13562510903050194

10. Martin, J., \& Nakayama, T. (2007). Intercultural communication in contexts (4th ed.). New York: McGraw-Hill.

11. Mayer, J.D. \& Salovey, P. (1997). What is emotional intelligence? In P. Salovey \& D Sluyter (Eds). Emotional development and emotional intelligence: Implications for educations (pp. 3-31) New York: New Basic Books

12. Oberst, U., Gallifa, J., Farriols, N., \& Vilaregut, A. (2009). Training Emotional and Social Competences in Higher Education: The Seminar Methodology. Higher Education in Europe, 34(3/4), 523-533. doi:10.1080/03797720903392243

13. Rubin, R., Palmgreen, R., \& Sypher, H. (1994). Communication research measures: A sourcebook. New York: The Guildford Press.

14. Vandervoort, D. J. (2006). The Importance of Emotional Intelligence in Higher Education. Current Psychology, 25(1), 3-7. Retrieved from EBSCOhost.

15. Wiemann, J. M. (1977). Explication and test of a model communicative competence. Human Communication Research, 3, 195-213.

16. Wong, C.-S., \& Law, K. S. (2002). The effects of leader and follower emotional intelligence on performance and attitude: An exploratory study. The Leadership Quarterly, 13, 243-274.

17. Wong, Chi-Sum \& Law, Kenneth S. (2002). The effects of leader and follower emotional intelligence on performance and attitude: An exploratory study. Leadership Quarterly, 13(3), 243-274.

18. Yarrish, K., \& Law, M. (2009). An exploration on the differences in emotional intelligence of first year students examined across disciplines within the school of business in a liberal arts college. Contemporary Issues in Education Research, 2 (4), 47-52. 